\title{
UNSUR PELESAPAN KALIMAT DALAM BUKU SISINDIRAN \\ JEUNG WAWANGSALAN ANYAR KARYA DÉDY WINDYAGIRI UNTUK BAHAN AJAR MENULIS SISINDIRAN DI SMP KELAS VIII
}

\author{
Triya Nugraha, Yayat Sudaryat, Hernawan \\ Departemen Pendidikan Bahasa Daerah FPBS UPI \\ Pos-el: triyachio@gmail.com, yayat.sudaryat@upi.edu, hernawan@upi.edu
}

\begin{abstract}
Abstrak
Latar belakang penelitian ini didasarkan pada kenyataan bahwa sisindiran merupakan susunan kalimat. Kalimat-kalimat yang terdapat pada sisindiran merupakan kalimat majemuk dan terdapat unsur yang dilesapkan. Penelitian ini mempunyai tujuan untuk mendeskripsikan unsur pelesapan dan bentuk pelesapan yang terdapat pada kalimat sisindiran serta pamakaiannya pada pembelajaran. Penelitian ini menggunakan metode penelitian deskriptif dengan menggunakan teknik studi dokumentasi untuk mengumpulkan data. Data dianalisis menggunakan analisis unsur langsung. Sumber data didapatkan dari buku Sisindiran jeung Wawangsalan Anyar karya Dédy Windyagiri. Hasil penelitian menemukan dua hal, yaitu unsur lesapan dan bentuk lesapan kalimat. Unsur lesapan meliputi 1) pelesapan tunggal yang mencakup pelesapan unsur S, P, O, dan Konj.; 2) pelesapan majemuk yang mencakup pelesapan unsur $\mathrm{S}+\mathrm{P}, \mathrm{S}+\mathrm{O}, \mathrm{S}+\mathrm{K}, \mathrm{S}+\mathrm{Pel}$., S+Konj., O+Konj., S+P+Konj., S+O+Konj., dan S+Pel.+Konj. Bentuk pelesapan kalimat berdasarkan prosesnya yang ditemukan adalah 1) delisi tékstual; 2) delisi situasional; dan 3) delisi struktural. Delisis situasional dan unsur lesapan subjek paling banyak ditemukan. Hal ini berhubungan dengan cara penyebarannya yang secara lisan, dalam obrolan langsung si pembicara jarang mengucapkan semua maksudnya secara lengkap karena pasti bisa dimengerti oleh lawan bicaranya dengan dibantu isyarat dari pembicara. Hasil penelitian pelesapan kalimat ini dapat dipakai untuk bahan pengajaran menulis sisindiran.
\end{abstract}

Kata kunci: unsur pelesapan, délisi, sisindiran, bahan ajar

\section{THE ELEMENT OF SENTENCE PHRASING IN SISINDIRAN JEUNG WAWANGSALAN ANYAR BOOK BY DEDY WINDYAGIRI FOR WRITING MATERIAL STUDY AT GRADE VIII JUNIOR HIGH SCHOOL}

\begin{abstract}
The background of this study is because of the reality that sisindiran consists of sentence. Sisindiran sentences is a compound sentence and there are deletion elements. This study aimed to describe deletion elements and the type of deletion contained in sisindiran sentence and its use in learning. This study used a descriptive method with documentation study techniques to collect data. A data analyzed with direct element analysis. Data sourced in Dedy Windyagiri's book, Sisindiran jeung Wawangsalan Anyar. The findings show there are two things, deletion elements and type of deletion elements. Deletion elements are: 1) single deletion are include deletion $S, P, O$, and Konj.. element; 2) plural deletion are include $S+P, S+O, S+K, \quad S+P e l ., \quad S+K o n j ., \quad O+K o n j ., \quad S+P+K o n j$. , $S+O+K o n j .$, dan $S+P e l .+K o n j$. elements. Deletion type based on the process that found are 1) textual deletion; 2) situational deletion; and 3) structural deletion. Situational deletion and subject deletion elements are the most found. That is related to the way they are spread orally. Results of this study is can be used for writing study material.
\end{abstract}

Keywords: deletion element, deletion, sisindiran, study material 


\section{PENDAHULUAN}

Kalimat transformasi merupakan kalimat yang strukturnya berbeda dengan kalimat inti tetapi masih bisa dimengerti makna kalimatnya. Salah satu bagian dari kalimat transformasi adalah kalimat lesapan, yaitu adanya salah satu unsur kalimat yang dihilangkan tanpa mengubah makna kalimat itu sendiri (Sudaryat, dkk. 2013, hal. 278).

Kalimat lesapan atau yang biasa disebut elipsis, banyak digunakan pada kehidupan sehari-hari baik ketika mengobrol dengan teman atau rekan kerja maupun dalam sebuah karya sastra. Khusus pada sastra, salah satunya adalah pada sisindiran dalam sastra Sunda atau yang lebih kita kenal dengan pantun. Pada sisindiran banyak menggunakan kalimat lesapan karena terpaku oleh aturan jumlah suku kata yang sama dan suara yang berima pada setiap larik, dengan begitu akan banyak kalimat pada sisindiran yang menghilangkan satu atau lebih unsur kalimatnya agar mendapatkan suku kata yang cocok. Walau pun demikian, tidak sedikit juga kalimat yang dipakai pada sisindiran itu merupakan kalimat lengkap.

Contoh sisindiran yang menggunakan kalimat lesapan:

Kelewih jeung siki sentul, campedak dikaparakeun.

Tebah-tebih abdi nyusul, tos pendak [abdi] disapirakeun.

(Windyagiri, 2011, kc. 26)

Kelewih dan biji sentul, cempedak di ke atapkan.

Jauh-jauh aku menyusul, sudah bertemu [aku] tak dihiraukan.

Pada kalimat isi sisindiran di atas terdapat unsur yang dilesapkan yaitu subjeknya, aku. Dihilangkannya subjek pada bagian isi tersebut agar suku kata nya sama dengan larik yang lain yaitu delapan suku kata. Jika subjek pada bagian isi tersebut tidak dihilangkan maka suku katanya akan menjadi 10 dan menyebabkan perbedaan jumlah suku kata dan kalimatnya kurang efektif.

Pada kehidupan sehari-hari, kalimat lesapan banyak dipakai dalam obrolanobrolan santai masyarakat umum. Misalnya ketika bertemu dengan teman di jalan, biasanya pembicara dan lawannya sering menggunakan kalimat yang singkat seperti: "Kemana?", lalu dijawab "Museum". Dalam proses pembelajaran di kelas pun demikian. Ada kalanya guru bertanya kepada siswa, "mengerti?", lalu siswa menjawab 'mengerti". Kedua obrolan tersebut hanya menggunakan satu unsur kalimat, tetapi pembicara dan lawannya saling mengerti tentang apa yang mereka bicarakan. Selain itu, masih banyak lagi contoh penggunaan kalimat lesapan di kehidupan sehari-hari.

Proses lesapan unsur kalimat disebut delisi. Menurut Sudaryat dkk. (2013, hal. 278), unsur yang dilesapkan bisa ditelusuri berdasarkan teks atau wacana tulisannya (delisi tekstual), konteks situasinya (delisi situasional), atau berdasarkan struktur kalimatnya (delisi struktural). Hal inilah yang harus diteliti, unsur lesapan apa saja yang ada pada buku Sisindiran jeung Wawangsalan Anyar karya Dédy Windyagiri, bagaimana proses pelesapannya, serta bagaimana kalimat lesapan pada sisindiran ini dijadikan bahan pembelajaran.

Penelitian mengenai unsur lesapan kalimat pernah dilakukan oleh Imas Khoerunisa pada tahun 2006 dengan judul peneltian "Sirnaan Unsur Fungsional Kalimah Dina Novel Mercedes 190 karya Muh. Rustandi Kartakusuma". Hasil penelitiannya yaitu memilah kalimat lesapan berdasarkan unsur-unsur lesapan kalimat pada novel yang dibagi menjadi dua yaitu, lesapan tunggal; unsur lesapannya ada satu, dan lesapan majemuk; unsur lesapannya lebih dari satu. 
Buku Sisindiran jeung Wawangsalan Anyar karya Dédy Windyagiri sendiri pernah diteliti oleh Hena Sumarni pada tahun 2016. Penelitiannya mengenai struktur kalimat pada sisindiran dan wawangsalan dengan judul "Kalimah dina Sisindiran jeung Wawangsalan Anyar karya Dédy Windyagiri (Ulikan Struktur jeung Semantik)". Menurut Sumarni (2016, hal. 39-41) kalimat yang digunakan pada Sisindiran jeung Wawangsalan Anyar karya Dédy Windyagiri secara keseluruhan merupakan kalimat majemuk. Selain itu, dibahas juga hubungan arti antar klausanya dan kekhasan kalimat pada sisindiran dan wawangsalan. Sedangkan kalimat lesapan tidak dibahas secara khusus dalam penelitiannya.

Untuk melengkapi ilmu pengetahuan mengenai kalimat lesapan, khususnya mengenai proses lesapan unsur kalimatnya, penulis bertujuan untuk menganalisis proses lesapan unsur kalimat pada sisindiran supaya bisa menambah pengetahuan bidang bahasa dan pembelajaran bahasa dengan judul "Unsur Sirnaan Kalimah dina buku Sisindiran jeung Wawangsalan Anyar Karya Dédy Windyagiri pikeun Bahan Ajar Nulis di SMP Kelas VIII'. Penelitian ini difokuskan untuk menganalisis proses lesapan unsur kalimat (delisi) serta penggunaannya jika dijadikan bahan pembelajaran menulis sisindiran di SMP kelas VIII.

\section{METODE PENELITIAN}

Penelitian ini menggunakan pendekatan kualitatif dengan menggunakan metode deskriptif. Metode deskriptif yaitu metode yang dipakai ketika ingin mendeskripsikan suatu hal yang terjadi pada masa sekarang. Metode deskriptif biasanya membahas mengenai bagaimana keadaan, proses, karakteristik, dan hasil dari suatu variabel atau lebih (Sudjana, 2006, hal. 52).
Menurut Arikunto (2010, hal. 234) penelitian deskriptif tidak memerlukan administrasi dan kontrol terhadap perlakuan. Penelitiannya hanya ditujukan untuk menggambarkan seadanya mengenai suatu variabel, gejala, atau keadaan. Umumnya penelitian deskriptif tidak dipakai untuk menguji suatu hipotesis.

Metode penelitian deskriptif dipakai karena dianggap sesuai dengan tujuan penelitian ini untuk menganalisis dan menggambarkan mengenai kalimat lesapan, khususnya proses lesapan unsurnya, pada buku Sisindiran jeung Wawangsalan Anyar karya Dedy Windyagiri tanpa adanya hipotesis.

Sumber data utama penelitian ini adalah buku Sisindiran jeung Wawangsalan Anyar karya Dedy Windyagiri. Pada buku ini banyak contoh sisindiran bentuk paparikan, rarakitan, dan wawangsalan. Selain itu, ada pula sisindiran dangding yang ditulis menggunakan aturan pupuh seperti pupuh Kinanti, Asmarandana, Sinom, dan Dangdanggula. Untuk penelitian ini, hanya sisindiran bentuk paparikan, rarakitan, dan sisindiran dangding saja yang dianalisis dengan jumlah 159 sisindiran.

Data dikumpulkan dengan menggunakan teknik studi dokumentasi. Studi dokumentasi dilakukan dengan cara mencari informasi tertulis yang merupakan karya ilmiah, bisa dari buku, essay, dokumen, jurnal, dll.

Instrumen penelitian adalah alat untuk memperoleh data yang yang harus dipilih sesuai dengan jenis data yang dibutuhkan (Sudjana, 2006, hal.58). Instrumen yang dipakai dalam penelitian ini adalah observasi tidak langsung dengan alat bantu berupa kartu data yang dipakai untuk memilah-milah proses lesapan unsur kalimat pada sisindiran. Data yang sudah terkumpul kemudian diolah dengan cara dianalisis menggunakan teknik analisis unsur langsung. 


\section{HASIL DAN PEMBAHASAN}

Suatu kalimat sekurang-kurangnya harus terdiri dari subjek (S) dan predikat (P), baik dilengkapi objek (O) dan pelengkap (peng.) ataupun tidak, bisa juga disebut kalimat dasar. Atau bisa saja ada unsur lain seperti keterangan (Ket.) atau konjungtor (Konj.). Berbeda dengan unsur-unsur yang terdapat pada kalimat lesapan. Pada kalimat lesapan terdapat unsur yang hilang ketika diucapkan atau ditulis tergantung konteks situasi ketika mengucapkan kalimat tersebut. Unsur yang dilesapkan bisa merupakan subjeknya, predikatnya, objeknya, keterangannya, atau pelengkapnya, dsb.

Kalimat pada sisindiran itu sendiri menurut Sumarni (2016, hal. 40-41), merupakan kalimat majemuk, baik bagian sampiran maupun isinya sama-sama menggunakan kalimat majemuk.

Data yang dianalisis berjumlah 159 sisindiran, tetapi hanya ada 151 sisindiran yang ditemukan adanya unsur lesapan baik pada bagian sampirannya saja, isinya saja, atau pun pada keduanya.

Posisi unsur lesapan kalimatnya berbeda-beda, ada yang terdapat pada bagian sampiran, ada yang pada bagian isi, ada pula yang terdapat pada keduanya. Hal ini sama dengan apa yang ditemukan oleh Khoerunnisa (2006, hal. 121-122) pada penelitiannya yang menyebutkan pelesapan unsur fungsional kalimat dilihat dari jenis unsur yang dilesapkan ada yang berupa kata, frasa, dan klausa. Dilihat dari posisi lesapan unsur kalimatnya ada menempati posisi di awal, di tengah, atau di akhir kalimat.

\section{Unsur Lesapan Kalimat}

Unsur lesapan yang ditemukan dari penelitian ini dibagi menjadi dua jenis berdasarkan jumlah unsur lesapan yang ditemukan dalam satu kalimat yaitu, lesapan tunggal dan lesapan majemuk. Lesapan tunggal yang ditemukan ada empat, yaitu; 1) lesapan subjek sejumlah 105 kalimat; 2) lesapan predikat sejumlah empat kalimat; 3) lesapan objek sejumlah dua kalimat; dan 4) lesapan konjungtor sejumlah 15 kalimat. Terlihat bahwa unsur subjek adalah yang paling banyak dilesapkan dan unsur predikat paling sedikit dilesapkan dalam lesapan tunggal.

Sedangkan pelesapan majemuk ada Sembilan, yaitu; 1) $\mathrm{S}+\mathrm{P}$ sejumlah lima kalimat; 2) S+O sejumlah 22 kalimat; 3) S+K sejumlah tujuh kalimat; 4) S+Pel. Sejumlah tiga kalimat; 5) S+Konj. Sejumlah lima kalimat; 6) $\mathrm{O}+$ Konj. satu kalimat; 7) $\mathrm{S}+\mathrm{P}+\mathrm{Konj}$. satu kalimat; 8) S+O+Konj. sejumlah empat kalimat; dan 9) S+Pel.+Konj. satu kalimat. Terlihat bahwa unsur $\mathrm{S}+\mathrm{O}$ adalah yang paling banyak dilesapkan dalam satu kalimat, sedangkan $\mathrm{O}+\mathrm{Konj}$., $\mathrm{S}+\mathrm{P}+$ Konj., dan S+Pel.+Konj. adalah yang paling sedikit.

Diantara unsur-unsur lesapan yang ditemukan, lesapan unsur subjek adalah yang paling banyak ditemukan baik dalam lesapan tunggal maupun lesapan majemuk tetap terdapat unsur subjeknya. Hal ini berhubungan dengan cara penyebaran sisindiran yang secara lisan. Kalimat yang diucapkan secara langsung oleh pembicara kepada lawan bicaranya pada konteks situasi tertentu sering kali menggunakan kalimat yang tidak lengkap. Oleh sebab itu, subjek kalimatnya sering tidak disebutkan karena sudah pasti dapat dimengerti oleh lawan bicaranya.

Berikut salah satu contohnya.
Abdi rék ka Cikapundung, [J] teu apal kiruh hilirna.
Abdi mah daék dicandung, sok asal puguh kilirna.

(SWA/40/S/49)

Aku akan ke Cikapundung,

[S] tidak tahu keruh bawahnya.

Aku bersedia dimadu, silahkan asal jelas kilirnya.

Terlihat dari contoh di atas terdapat lesapan unsur subjek (jejer) pada bagian sampirannya. Walaupun subjek pada klausa kedua di bagian sampiran tidak 
disebutkan, tetapi lawan bicaranya pasti akan mengerti siapa yang dimaksud tidak tahu keruh bawahnya oleh pembicara karena sudah jelas sisindiran tersebut mencerikatan pembicaranya sendiri. Apabila unsur subjeknya tidak dilesapkan, kalimatnya menjadi seperti di bawah ini.

Abdi rék ka Cikapundung, [abdi] teu apal kiruh hilirna.
Abdi mah daék dicandung, sok asal puguh kilirna.

(SWA/40/S/49)

Aku akan ke Cikapundung, [aku] tidak tahu keruh bawahnya. Aku bersedia dimadu, silahkan asal jelas kilirnya

Agar lebih jelas proses lesapannya bisa dilihat pada diagram di bawah.

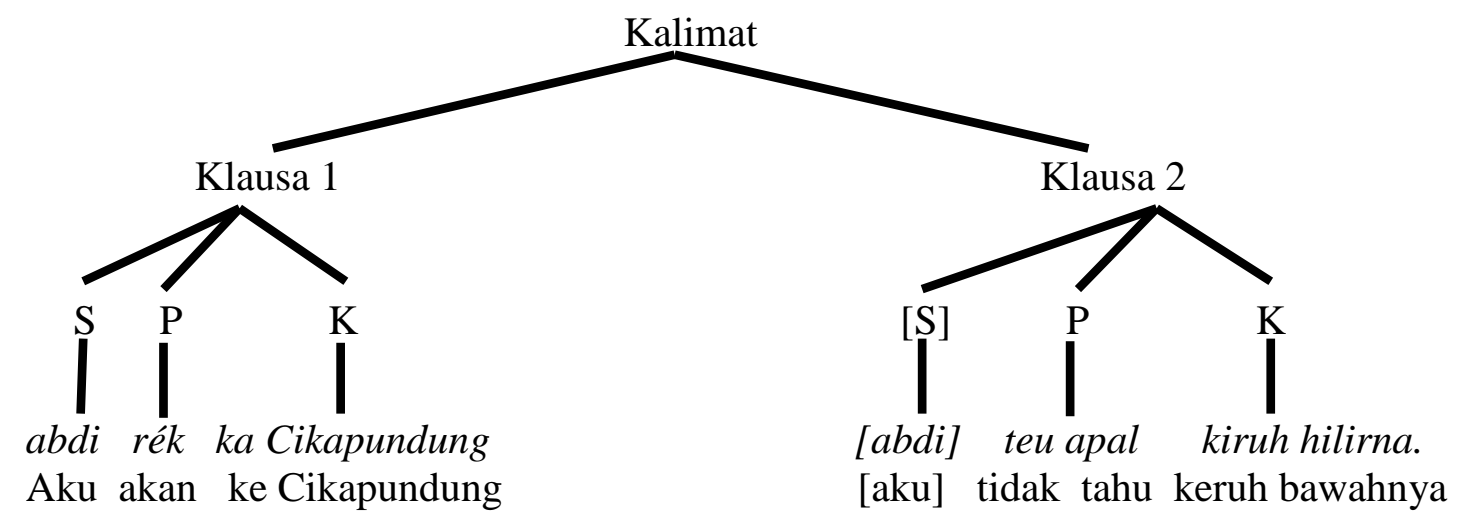

Kalimat pada sisindiran tersebut merupakan kalimat majemuk yang berpola $\mathrm{S}+\mathrm{P}+\mathrm{K}$, dan pada klausa keduanya tidak memiliki subjek atau subjeknya dilesapkan.

Unsur pelengkap merupakan unsur yang paling jarang dilesapkan, tidak ada pada lesapan tunggal dan dalam lesapan majemuk pun hanya ada empat yaitu, pada $S+P e l$. ada tiga, dan pada S+Pel.+Konj. ada satu. Contohnya pada kalimat isi sisindiran di bawah.

Ka halte megat nu ngalih, di bumi tos diantosan.

[J] Mugi henteu rengat galih, abdi mah tos ditarosan [pang.].

Ke halte jemput yang pindah, di rumah sudah ditunggu.

[S] Semoga tidak patah hati, aku telah dilamar [Pel.].

Jika unsurnya tidak dilesapkan, kalimatnya menjadi seperti ini.

Ka halte megat nu ngalih, di bumi tos diantosan. [Akang] mugi henteu rengat galih, abdi mah tos ditarosan [lalaki séjén/si A].

(SWA/33/SA/50)

Ke halte jemput yang pindah, di rumah sudah ditunggu. [Akang] semoga tidak patah hati, aku telah dilamar [pria lain/si A]. 


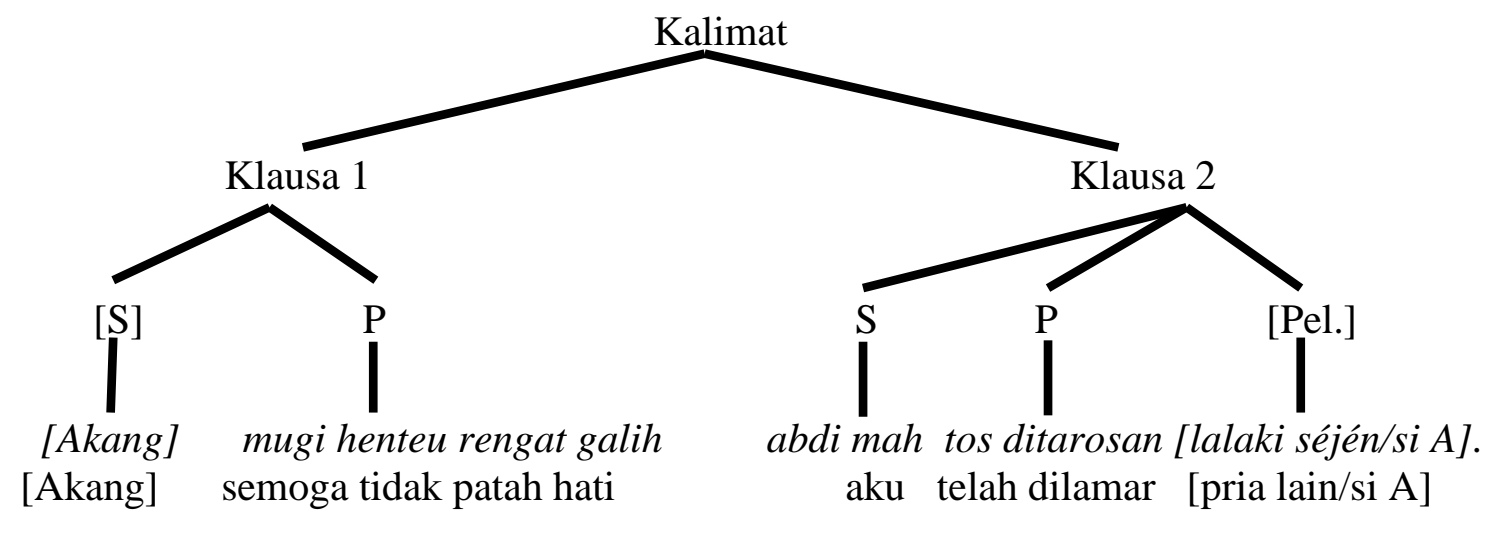

Alasan unsur pelengkap jarang dilesapkan adalah karena kalimat sisindiran-nya banyak yang tidak membutuhkan pelengkap. Dalam contoh di atas, kalimatnya membutuhkan pelengkap supaya informasinya lebih jelas dan tidak menimbulkan pertanyaan 'siapa yang telah melamar kamu?' atau sebagainya. Mungkin saja jika hanya ditujukan pada satu orang, tidak menggunakan pelengkap pun, orang yang diajak bicara tidak akan mempertanyakan siapa yang telah melamar. Tetapi, berbeda lagi jika ditujukan pada banyak orang, mereka (lawan bicara) akan bertanya-tanya siapa yang telah melamarnya.

Selain yang sudah disebutkan sebelumnya, alasan lain adanya pelesapan unsur kalimat pada sisindiran yaitu untuk menyesuaikan jumlah suku kata pada tiap lariknya dan agar kalimatnya lebih efektif juga enak diucapkan. Pada umumnya sisindiran dibentuk oleh delapan suku kata tiap larik, atau jumlah lain yang genap.

\section{Bentuk Kalimat Lesapan}

Delisi atau elipsis sudah biasa dilakukan pada kalimat majemuk atau majemuk bertingkat menurut kaidahkaidah tertentu.

1) Jika subjek klausa-klausa pada kalimat majemuk atau majemuk bertingkat sama, biasanya subjek klausa yang diawali oleh konjungtor sering dihilangkan.

2) Jika subjek pada klausa yang diawali atau didahului oleh konjungtor berbeda dengan subjek klausa yang tidak didahului konjungtor maka subjek tersebut tidak boleh dihilangkan.

3) Delisi predikat, objek, dan keterangan bisa dilakukan asalkan unsur-unsur pada kedua klausa tersebut sama.

Dalam Tata Basa Sunda Kiwari, Sudaryat dkk. (2013, hal. 278-280) menyebutkan ada tiga jenis kalimat lesapan berdasarkan proses atau cara ditemukannya unsur lesapan tersebut, yaitu; (1) delisi tekstual, (2) delisi struktural, dan (3) delisi situasional.

Semua jenis kalimat lesapan ini ditemukan pada sisindiran yang telah dianalisis.

\section{Delisi Tekstual}

Delisi tekstual yaitu dimana unsur lesapan kalimatnya bisa ditemukan pada teks atau wacananya sendiri. Delisi tekstual yang ditemukan sejumlah 62, ada yang menempati pada klausa pertama, ada juga yang menempati klausa kedua salah satu bagian sisindiran. Contohnya:

Ka halte megat nu ngalih, di bumi [nu ngalih] tos diantosan. Mugi henteu rengat galih, abdi mah tos ditarosan.

(SWA/33/SA/50)

Ke halte jemput yang pindah, di rumah [yang pidah] sudah ditunggu. 
Semoga tidak hancur hati, aku telah dilamar.

Pada klausa kedua dibagian sampiran sisindiran di atas terdapat unsur yang dilesapkan yaitu subjeknya, yang pindah. Unsur lesapan tersebut bisa ditemukan pada teksnya sendiri, yaitu pada klausa pertamanya 'ke halte jemput yang pindah'. Tanpa disebutkan pada klausa keduanya pun kalimat tersebut masih bisa dimengerti oleh lawan bicaranya karena sudah jelas bahwa dalam kalimat tersebut pembicaranya sedang menceritakan orang yang pindahan. Delisi tekstual adalah proses pembentukan kalimat lesapan yang paling mudah dimengerti dan diteliti karena unsur yang hilang dapat dtemukan pada teks atau wacananya secara langsung.

\section{Delisi Situasional}

Delisi situasional yaitu dimana unsur yang dilesapkannya dapat ditemukan jika kita mengerti konteks situasi ketika diucapkannya kalimat tersebut. Delisi situasional paling banyak ditemukan yaitu ada 126, hal ini berhubungan dengan lesapan subjek yang merupakan unsur yang paling banyak dilesapkan.

Untuk delisi situasional, setiap orang akan mempunyai persepsi yang berbeda tentang apa yang dimaksudkan oleh pembicaranya. Terutama dalam delisi pada teks kalimat karena pembaca tidak akan melihat secara langsung sedang dalam kondisi dan situasi seperti apa kalimat tersebut ditulis. Umumnya dalam delisi situasional, unsur yang dilesapkannya adalah subjek.

Perhatikan contoh di bawah.

Balukang suligar mayang
[kuring] ngala combrang maké
parang
[urang] Rumingkang ngumbar
kahayang
[urang] mindeng nyorang nu
dilarang [ku Alloh swt.]

[kuring] ngala combrang maké parang

[urang] Rumingkang ngumbar

[urang] mindeng nyorang $n u$ dilarang [ku Alloh swt.]

\begin{abstract}
Balukang suligar mayang
[aku] memetik combrang dengan parang

[kita] hidup mengumbar keinginan

[kita] sering melakukan yang dilarang [Allah swt.]
\end{abstract}

(SWA/26/P/48)

Kata aku [S], kita [S], dan Allah swt. [O] merupakan unsur-unsur yang dilesapkan. Unsur-unsur tersebut bisa ditemukan berdasarkan konteks situasinya yaitu ketika seseorang sedang memberikan pepatah kepada orang lain, satu orang atau pun lebih.

Pada bagian sampiran terdapat lesapan subjek, aku, dimana unsur tersebut tidak diucapkan sebab sudah pasti dapat dimengerti oleh lawan bicaranya. Sebenarnya, unsur subjek tersebut bisa jadi bukan aku apabila dilihat dari kalimatnya, tapi dikarenakan kalimat itu diucapkan oleh pembicaranya, lawan bicaranya pasti mempunyai anggapan bahwa yang memetik combrang itu adalah pembicaranya (aku).

Begitu pula pada bagian isinya ada lesapan subjek (kita) dan objek (Allah swt.). Sudah menjadi kebiasaan dimana pun jika ada yang memberi pepatah selalu ditujukan pada lawan bicaranya secara langsung menggunakan kata ganti 'kamu' atau 'kalian'. Selain itu tidak jarang juga pepatah tersebut ditujukan pada orang lain dan dirinya sendiri menggunakan kata ganti 'kita'.

Kemudian, sebagai umat muslim pasti sudah mengerti bahwa adanya larangan itu berasal dari Allah swt. Sebenarnya, setiap orang akan mempunyai persepsi yang berbeda pada objek kalimat ini. Jika orang yang sedang diajak berbicara adalah seorang nonmuslim, tentunya akan mempunyai persepsi yang berbeda, misalnya akan beranggapan bahwa larangan yang dimaksud adalah larangan dari Dewa atau sebagainya

Agar bisa mengerti maksud kalimat lesapan yang prosesnya secara 
situasional, tentu saja harus mengerti terlebih dahulu kira-kira pada konteks situasi seperti apa kalimat tersebut diucapkan. Jika tidak mengerti, akan kebingungan untuk memahami maksud kalimatnya.

\section{Delisi Struktural}

Delisi struktural yaitu dimana unsur lesapan kalimatnya bisa ditemukan berdasarkan pengetahuan kita mengenai struktur kalimat. Delisi struktural yang ditemukan berjumlah 53. Secara struktural, unsur lesapan yang ditemukan merupakan konjungtor, terutama pada bagian sampiran yang banyak menyebutkan barang dalam satu kalimat. Adapun yang ditemukan pada kalimat yang berupa perbandingan. Selain itu, ditemukan juga pada kalimat majemuk atau majemuk bertingkat.

Berikut contoh kalimat sisindiran yang mengalami delisi struktural.

Ka Cipacing [jeung] ka
Ciléngkrang,
[tuluy] ka Cileunyi dagang bilik.
Bagja teuing diri engkang,
lamun Nyai kapimilik.

(SWA/28/SA/13)

Ke Cipacing [dan] ke Cilengkrang, [lalu] ke Cileunyi menjual bilik.

Betapa bahagianya diriku,

jika kamu dapat kumiliki.

Kata 'dan' pada klausa pertama bagian sampiran merupakan konjungtor yang menyambungkan dua predikat berbeda. Sedangkan kata 'lalu' pada klausa keduanya merupakan konjungtor yang menyambungkan klausa pertama dan kedua yang merupakan kalimat majemuk bertingkat.

Seperti yang kita ketahui, bahwa untuk menuliskan dua kata atau lebih dengan fungsi yang sama harus menggunakan konjungtor. Dan dalam kalimat majemuk bertingkat memerlukan konjungtor untuk menghubungkan klausa pertama dan klausa keduanya.

Mengidentifikasi kalimat lesapan yang dibentuk secara delisi struktural memang tidak akan mudah, apalagi bagi orang-orang yang kurang mengerti ilmu kebahasaan, khususnya mengenai struktur pembentukan kalimat. Delisi struktural paling sedikit ditemukan karena memang tidak terlalu banyak kalimat sisindiran yang membutuhkan konjungtor untuk menyambungkan antar frasa atau klausanya.

\section{Bahan Pembelajaran Menulis Sisindiran}

Menurut Haerudin dan Kardana (2013, hal. 81), bahan pembelajaran bahasa Sunda erat kaitannya dengan materi pokok. Richards \& Rodgers dalam Tarigan (2009, hal. 19) menjelaskan bahan pembelajaran pada suatu sistem instruksional mencakup spesifikasi seperti berikut ini.

1) Matéri/bahan bisa menjadikan peserta untuk maju dan berkembang sesuai dengan kemampuan belajarnya masing-masing.

2) Matéri/bahan bisa menimbulkan adanya gaya belajar yang berbeda.

3) Matéri/bahan pembelajaran memberi kesempatan untuk studi dan pemakaian materi.

4) Matéri/bahan pembelajaran memberi kesempatan untuk mengevaluasi dan kemajuan dalam pembelajaran.

Menurut Abidin (2013, hal. 181) menulis merupakan suatu proses komuniksi secara tidak langsung antara penulis dan pembaca. Tulisan dibuat agar dimengerti maksud dan tujuannya sehhingga semua proses yang dilakukan penulis tidak percuma.

Menulis sendiri merupakan salah satu dari empat keterampilan berbahasa. Tidak berbeda dengan pembelajaran membaca, menyimak, dan bercerita, pada 
pembelajaran menulis pun diperlukan suatu metode agar bisa mencapai kompetensi pembelajaran menulis yang harus dimiliki peserta didik. Menurut Abidin (2013, hal. 184-187) ada tiga tahapan dalam proses menulis yaitu mendapatkan ide, mengolah ide, dan produksi ide. Tujuan pembelajaran menulis yaiutu untuk; (1) menumbuhkan kesadaran menulis pada siswa; (2) mengembangkan kemampuan menulis siswa; dan (3) agar siswa bisa menulis secara kreatif.

Unsur lesapan pada sisindiran bisa diterapkan untuk pembelajaran menulis sisindiran. Kenapa harus pembelajaran menulis? Sebab kalimat lesapan akan lebih mudah ditemukan dalam bentuk wacana tulisan. Jika pada pembelajaran bercerita, siswa akan kesulitan menemukannya karena kalimatnya tidak terlihat dan harus ditalar terlebih dahulu.

Pada umumnya sisindiran dibentuk oleh empat larik, dua sampiran dua isi. Syarat utama membuat sisindiran yaitu suku kata setiap larik harus sama dan mempunyai rima atau suara akhir yang sama antara sampiran dan isi.

Walau pun banyak sisindiran yang mempunyai unsur lesapan, akan tetapi makna kalimatnya tidak berubah dan masih bisa dimengerti oleh lawan bicaranya. Adanya unsur lesapan pada sisindiran ini dipengaruhi oleh aturan penulisannya yang harus mempunyai jumlah suku kata yang sama dan suara akhir yang berima.

Sesuai dengan Kurikulum 2013, pembelajaran sisinidiran yang digunakan adalah untuk SMP kelas VIII. Sesuai dengan kompetensi dasar.

3.4 Memahami dan mengidentifikasi fungsi sosial, struktur dan unsur kebahasaan dari sisindiran.

4.4 Mengekspresikan sisindiran dalam bentuk tulisan dan lisan.

Pada kompetensi dasar materi sisindiran disebutkan bahwa siswa harus paham mengenai struktur dan unsur kebahasaan dalam sisindiran. Oleh karena itu, perlu dilakukan evaluasi yang mendukung dan sesuai dengan kompetensi dasar yang harus dimiliki oleh siswa.

Tentu saja sebelum siswa diberi soal evaluasi, siswa harus diberi pembahasan terlebih dahulu mengenai apa dan seperti apa pembelajaran menulis itu dengan memperhatikan proses dan tujuan pembelajaran menulis sebagaimana yang diutarakan oleh Abidin.

Kemudian jelaskan juga mengenai struktur kalimat sisindiran yang merupakan kalimat majemuk, unsur apa saja yang membentuk kalimat tersebut, dan aturan yang menjadi patokan untuk menulis sisindiran seperti, jumlah larik perbaitnya, jumlah suku kata yang digunakan dalam setiap larik, suara yang harus berima antara sampiran dan isi. Jelaskan juga bahwa unsur yang membentuk kalimat sisindiran tidak selamanya lengkap, tetapi ada beberapa unsur yang boleh dihilangkan agar mempunyai jumlah suku kata yang sama dan rima yang sesuai dengan catatan kalimat yang ditulis masih bisa dimengerti maksud dan tujuannya.

\section{KESIMPULAN}

Semua unsur lesapan dikelompokan menjadi dua berdasarkan jumlah unsur lesapannya yaitu lesapan tunggal dan lesapan majemuk. Lesapan tunggal adalah kalimat yang mempunyai satu unsur lesapan yang mencakup pelesapan unsur S, P, O, dan Konj., sedangkan lesapan majemuk adalah kalimat yang mempunyai dua atau lebih unsur yang dilesapkan yang mencakup pelesapan unsur S+P, S+O, S+K, S+Pel., S+Konj., O+Konj., S+P+Konj., S+O+Konj., dan S+Pel.+Konj.. Unsur subjek merupakan unsur yang paling banyak dilesapkan.

Bentuk kalimat lesapan yang ditemukan dalam sisindiran dikelompokan menjadi tiga berdasarkan 
proses lesapan unsurnya. Pertama, delisi tekstual, dimana unsur lesapan kalimatnya bisa ditemukan dari teksnya sendiri. Kedua, delisi situasional, unsur lesapan kalimatnya bisa ditemukan apabila melihat konteks situasi ketika kalimat itu diucapkan. Ketiga, delisi struktural, dimana unsur lesapan kalimatnya bisa ditemukan berdasarkan pengetahuan kita mengenai struktur kalimat. Delisi situasional merupakan proses lesapan yang paling banyak ditemukan dan hal ini berhubungan dengan lesapan unsur subjek yang merupakan unsur yang paling banyak dilesapkan dikarenakan cara penyebaran sisindiran yang secara lisan jarang menyebutkan subjeknya.

Sesuai dengan kompetensi dasar yang ada pada Kurikulum 2013 bahwa siswa harus memahami stuktur dan unsur kebahasaan dalam sisindiran, maka perlu diadakan evaluasi pembelajaran yang sesuai dengan kompetensi dasar yang harus dimiliki oleh siswa.

Akan tetapi, sebelum siswa diberi soal evaluasi, siswa harus diberi pembahasan terlebih dahulu mengenai struktur kalimat sisindiran yang merupakan kalimat majemuk, unsur apa saja yang membentuk kalimat tersebut, dan aturan yang menjadi patokan untuk menulis sisindiran seperti, jumlah larik perbaitnya, jumlah suku kata yang digunakan dalam setiap larik, suara yang harus berima antara sampiran dan isi, dsb. tanpa melupakan tujuan dari pembelajaran menulis tersebut.

\section{DAPTAR PUSTAKA}

Abidin, Yunus. 2013. Pembelajaran bahasa berbasis pendidikan karakter. Bandung: PT Refika Aditama.
Arikunto, Suharsimi. 2010. Manajemen penelitian. Jakarta: PT Rineka Cipta.

Dinas Pendidikan Provinsi Jawa Barat. 2013. Mulok pelajaran bahasa daerah kurikulum 2013. Bandung: Dinas Pendidikan Provinsi Jawa Barat.

Haerudin, Dingding \& Kardana. 2013. Panganteur talaah buku ajar. Bandung : JPBD UPI.

Khoerunnisa, Imas. 2006. Sirnaan Unsur Fungsional Kalimah dina Novel Mercedes 190 Karya Muh. Rustandi Kartakusuma. Skripsi Pendidikan Bahasa Daerah. Bandung: Teu dipedalkeun.

Sudaryat, Yayat spk. 2013. Tata basa sunda kiwari. Bandung : Yrama Widya.

Sudjana, Nana. 2006. Tuntunan penyusunan karya ilmiah, makalahskipsi-tesis-disertasi. Bandung : Sinar Baru Algesindo.

Sumarni, Hena. 2016. Kalimat dalam Sisindiran Dan Wawangsalan Anyar Karya Dédy Windyagiri (Kajian Struktur dan Semantik). Jurnal Lokabasa Vol. 7, No. 1, April. Bandung: Departemen Pendidikan Bahasa Daerah.

Tarigan, Henri Guntur. 2009. Metodologi pengajaran bahasa 1. Bandung: Angkasa.

Windyagiri, Dedi. 2011. Sisindiran jeung Wawangsalan Anyar. Bandung: PT Kiblat Buku Utama.

\section{UCAPAN TERIMA KASIH}

Terima kasih kepada pengelola jurnal yang telah menerbitkan tulisan ini, serta kepada penulis terdahulu yang karya atau bukunya dikutip dalam tulisan ini 